Sherif Beniameen Mossad, MD, FACP, FIDSA, FAST

Department of Infectious Diseases, Respiratory Institute and Transplant

Center, Cleveland Clinic; Professor of Medicine, Cleveland Clinic Lerner Col-

lege of Medicine of Case Western Reserve University, Cleveland, $\mathrm{OH}$

\title{
Another influenza season in the shadow of the COVID-19 pandemic
}

$\mathrm{T}$ he 2020 to 2021 influenza season took a backstage to the COVID-19 pandemic, when the COVID-19 vaccines were in their initial stages of distribution in the northern hemisphere. Although only $50 \%$ to $55 \%$ of US adults received the 2020 to 2021 influenza vaccination, ${ }^{1,2}$ influenza activity was very low compared with prior seasons, ${ }^{1,2}$ certainly the result of behavioral measures instituted to mitigate the COVID-19 pandemic.

With the current 2021 to 2022 influenza season coinciding with another increase of COVID-19 cases, lower COVID-19 vaccine uptake and relaxed mitigation measures in

Routine

age-appropriate

vaccination

of all persons

$\geq 6$ months of

age without

contraindica-

tions continues

to be

recommended some areas of the United States have resulted in vaccine breakthroughs, increased hospitalizations, and an ominous milestone of more than 722,000 deaths. $^{3}$

Vaccinations, in general, are helping ease the strain of the upcoming influenza season, with an estimated $62 \%$ of Americans experiencing immunity against COVID-19 as a result of prior infection or immunization. ${ }^{4}$ Further, a recent, retrospective cohort study involving 74,754 patients showed that COVID-19-positive patients were less likely to develop sepsis, stroke, deep venous thrombosis, require admission to the intensive care unit, or subsequent emergency department visits if they received influenza vaccination 2 weeks to 6 months prior to their COVID-19-positive diagnosis. ${ }^{5}$

\section{US CENTERS FOR DISEASE CONTROL AND PREVENTION GUIDANCE}

Currently, no data suggest that the COVID-19 pandemic impacted seasonal influenza virus mutations, and the 2021 to 2022 influ-

enza vaccine available in the United States includes updated influenza A(H1N1)pdm09 and influenza $\mathrm{A}(\mathrm{H} 3 \mathrm{~N} 2)$ components. ${ }^{6}$ All US influenza vaccines for the 2021 to 2022 season are quadrivalent, and routine ageappropriate vaccination of all persons $\geq 6$ months of age without contraindications continues to be recommended. ${ }^{6}$ Primary updates by the US Centers for Disease Control and Prevention (CDC) Advisory Committee on Immunization Practices (ACIP) to this season's influenza vaccination ${ }^{6}$ include the following:

- US-licensed influenza vaccines available for the 2021 to 2022 influenza season are egg-based inactivated influenza vaccines (IIV4s), cell culture-based inactivated influenza vaccines [Flucelvax Quadrivalent (ccIIV4)], recombinant influenza vaccines (RIV4), and live attenuated influenza vaccines (LAIV4). ${ }^{6}$

- The approved age indication for ccIIV4 has been expanded from ages $\geq 4$ years to $\geq 2$ years. ${ }^{6}$

- Current guidance states that influenza and COVID-19 vaccines can be coadministered on the same day as well as within 14 days of each other ${ }^{7}$ and should be administered in separate anatomic sites. ${ }^{6}$ Providers should consult current ACIP COVID-19 vaccine recommendations and CDC guidance if concerned about coadministration. ${ }^{6}$

- Pregnant women should consider vaccination with IIV4, ccIIV4, or RIV4 in the third trimester, but not LAIV4 at any time during pregnancy or postpartum. ${ }^{6}$

- Regarding the timing of influenza vaccination, the new recommendation this 
year was that vaccine administration to nonpregnant adults should be after August and ideally before the end of October to optimize vaccine protection during the expected seasonal epidemics. ${ }^{6}$ This new recommendation is expected to continue into the future.

- A history of severe allergic reaction to IIV4s, RIV4, or LAIV4 other than urticaria (such as angioedema, respiratory distress, lightheadedness, or recurrent emesis) or requiring epinephrine or emergency medical intervention is now considered a precaution, not a contraindication for ccIIV4. Similarly, a history of severe allergic reaction to IIV4s, ccIIV4, or LAIV4 other than the aforementioned reactions is now considered a precaution, not a contraindication for RIV4. These patients should be vaccinated in an inpatient or outpatient medical setting, supervised by a healthcare provider who is able to recognize and manage such reactions. ${ }^{6}$

\section{OTHER INFLUENZA VACCINATION RECOMMENDATIONS}

Other relevant issues pertaining to influenza vaccination during the ongoing COVID-19 pandemic have been outlined. ${ }^{6-8}$ Influenza vaccine recipients and those who administer these vaccines should recognize that vaccine side effects can mimic COVID-19. ${ }^{7}$ Nevertheless, those who develop fever after vaccination should stay home until they defervesce for 24 hours without the use of antipyretics. ${ }^{?}$ Importantly, if fever persists or new respiratory symptoms develop, patients should contact their healthcare provider. ${ }^{?}$

In a nonprobability-based, convenience sample of 698 US adults infected with SARS-CoV-2 and 2,437 uninfected adults, $65.9 \%$ of those infected experienced longterm symptoms lasting $>4$ weeks while $42.9 \%$ of those uninfected reported such symptoms, representing an emerging public health concern. ${ }^{8}$ This may impact influenza vaccine uptake, as well as recognition of influenza-like illness; deferring influenza vaccination until resolution of another acute viral illnesses, such as COVID-19 is generally recommended. ${ }^{9}$ Safe vaccination practice calls for postponing influenza vaccination for those in quarantine after $\mathrm{CO}$ VID-19 exposure or in isolation after mild COVID-19 illness for 10 days, and after severe COVID-19 illness for 20 days. ${ }^{6}$

\section{COVID-19 AND INFLUENZA COINFECTION}

With several common clinical features of influenza and COVID-19, the overlap of the two epidemics occurring at the same time can complicate diagnosis, treatment, and prognosis. ${ }^{10}$ Although a small proportion of COV. ID-19 patients are coinfected with influenza, the risk for high-risk individuals is of concern. ${ }^{10}$ While both have some distinct features (Table 1), ${ }^{11,12}$ they can be hard to distinguish.

\section{VACCINE EFFICACY}

Safety and efficacy of the influenza vaccination for pregnant women has been documented, and a recent study noted $91.5 \%$ efficacy of transfer of antibodies in preventing hospitalization of newborns and infants, in whom the vaccine is not approved before 6 months of age. ${ }^{13}$ Another recent study has shown safety and humoral immunogenicity of messenger ribonucleic acid COVID-19 vaccines in maternal sera, as well as cord blood and breast milk, indicating transfer of immunity to neonates. ${ }^{14}$

A recent study showed that COVID-19 vaccination of healthcare workers reduces the risk of COVID-19 in members of their households. ${ }^{15}$ Indirect effects of influenza vaccination have been shown to be greater than direct effects, with 4 to 7 times the influenza cases prevented in non-vaccinated compared with vaccinated individuals, and complications including influenza-associated deaths among the unvaccinated elderly reduced by a factor of 20 to $30 .{ }^{16}$

Researchers have been evaluating both influenza and COVID-19 vaccination efficacy in how they decrease risk of infection and reduce disease severity in breakthrough infections. ${ }^{17}$ Currently approved or emergently authorizedfor-use COVID-19 vaccines trigger innate, durable immunity, although the emergence of protein variants could potentially limit efficacy. ${ }^{18}$ Preliminary data suggest that enhancing the interferon response could offer an immu-

\section{Current} guidance states that influenza and COVID-19 vaccines can be coadministered on the same day as well as within 14 days of each other 


\section{TABLE 1}

\section{Distinct features of influenza and COVID-19}

\begin{tabular}{|c|c|c|}
\hline & Influenza & COVID-19 \\
\hline Seasonality & Fall-winter & Year-round \\
\hline \multicolumn{3}{|l|}{ Annual incidence } \\
\hline Overall & $8 \%(3 \%-11 \%)$ & $6 \%-8 \%$ \\
\hline Children & $20 \%$ (unvaccinated) & Not applicable (no vaccine) \\
\hline Adults & $10 \%$ (unvaccinated) & $6 \%-8 \%$ (unvaccinated) \\
\hline Age distribution & Children $>$ adults & Adults $>$ children \\
\hline Incubation period (days) & $1-4$ days & $2-14$ days \\
\hline Duration of infectivity & $\begin{array}{l}1 \text { day before to } 7 \text { days after onset of } \\
\text { illness }\end{array}$ & $\begin{array}{l}2 \text { days before to } 10 \text { ( } 20 \text { for severe cases) } \\
\text { days after onset of illness }\end{array}$ \\
\hline Onset of symptoms & More acute & More subacute \\
\hline $\begin{array}{l}\text { Super-spreaders } \\
\text { (1 person infects } 8 \text { persons) }\end{array}$ & Not reported & $1 \%$ \\
\hline $\begin{array}{l}\text { Typical or characteristic features at onset } \\
\text { of illness }\end{array}$ & Fever, headache, dry cough & Loss of sense of taste or smell \\
\hline \multicolumn{3}{|l|}{ Severity of illness } \\
\hline Asymptomatic & $5 \%-50 \%$ & $30 \%-40 \%$ \\
\hline \multicolumn{3}{|l|}{ Symptomatic } \\
\hline Mild & $98 \%$ & $80 \%$ \\
\hline Moderate & $1 \%-2 \%$ & $15 \%$ \\
\hline Severe & $0.2 \%$ & $5 \%$ \\
\hline Fatal & $0.04 \%-0.1 \%$ & $3 \%-4 \%$ \\
\hline Duration of acute illness & $5-7$ days & $2-6$ weeks \\
\hline $\begin{array}{l}\text { Incidence of long-term symptoms lasting } \\
\text { longer than } 4 \text { weeks }\end{array}$ & $\begin{array}{l}\text { Clinically silent viral shedding for } \\
\text { weeks to months in immunocompro- } \\
\text { mised individuals }\end{array}$ & $60 \%-70 \%$ regardless of viral shedding \\
\hline \multirow[t]{2}{*}{ Complications } & Pneumonia & \multirow{2}{*}{$\begin{array}{l}\text { Deep venous thrombosis and pulmonary } \\
\text { embolism } \\
\text { Multisystem inflammatory disorders }\end{array}$} \\
\hline & $\begin{array}{l}\text { Exacerbation of underlying chronic } \\
\text { heart and lung diseases }\end{array}$ & \\
\hline
\end{tabular}

nological advantage to control viral infections. ${ }^{19}$

\section{FUTURE DIRECTION}

Hopefully, COVID-19 will eventually become an endemic viral infection with predictable annual (or other interval) epidemics. It would make perfect sense for developing combined universal influenza and COVID-19 vaccinations, as several pharmaceutical companies are in the process of developing. ${ }^{20,21}$

\section{DISCLOSURES}

The author reports no relevant financial relationships which, in the context of his contributions, could be perceived as a potential conflict of interest. 


\section{REFERENCES}

1. US Centers for Disease Control and Prevention. FluView. Weekly influenza surveillance report. https://www.cdc. gov/flu/weekly/index.htm. Accessed October 20, 2021.

2. US Centers for Disease Control and Prevention. 2020-2021 flu season summary. https://www.cdc.gov/flu/ season/faq-flu-season-2020-2021.htm. Accessed October 20, 2021.

3. US Centers for Disease Control and Prevention. COVID-19 Data Tracker. https://covid.cdc.gov/coviddata-tracker/\#vaccinations_vacc-total-admin-rate-total. Accessed October 22, 2021.

4. Moghadas SM, Sah P, Shoukat A, Meyers LA, Galvani AP. Population immunity against COVID-19 in the United States. Ann Intern Med 2021; Sep 14:M21-M2721. doi:10.7326/M21-2721

5. Taghioff SM, Slavin BR, Holton T, Singh D. Examining the potential benefits of the influenza vaccine against SARSCoV-2: a retrospective cohort analysis of 74,754 patients. PLoS One 2021;16(8):e0255541. doi:10.1371/journal.pone.0255541

6. Grohskopf LA, Alyanak E, Ferdinands JM, et al. Prevention and control of seasonal influenza with vaccines: recommendations of the Advisory Committee on Immunization Practices, United States, 2021-22 influenza season. MMWR Recomm Rep 2021; 70(5):1-28. doi:10.15585/mmwr.rr7005a1

7. US Centers for Disease Control and Prevention. Interim guidance for routine and influenza immunization services during the COVID-19 pandemic. https://www.cdc. gov/vaccines/pandemic-guidance/index.html. Accessed October 20, 2021.

8. Wanga V, Chevinsky JR, Dimitrov LV, et al. Long-term symptoms among adults tested for SARS-CoV-2-United States, January 2020-April 2021. MMWR Morb Mortal Wkly Rep 2021; 70(36):1235-1241. doi:10.15585/mmwr.mm7036a1

9. US Centers for Disease Control and Prevention. Adult Vaccination Resources: Standards for Adult Immunization Practice. https://www.cdc.gov/vaccines/hcp/adults/ for-practice/standards/index.html. Accessed October 20, 2021.

10. US Centers for Disease Control and Prevention. Similarities and differences between flu and COVID-19. https:// www.cdc.gov/flu/symptoms/flu-vs-covid19.htm. Accessed October 20, 2021
11. US Centers for Disease Control and Prevention. Influenza. Background and Epidemiology. https://www.cdc. gov/flu/professionals/acip/background-epidemiology.htm. Accessed October 20, 2021.

12. Dadashi M, Khaleghnejad S, Abedi Elkhichi P, et al. COVID-19 and influenza co-infection: a systematic review and meta-analysis. Front Med (Lausanne) 2021 Jun 25;8:681469. doi:10.3389/fmed.2021.681469

13. Benowitz I, Esposito DB, Gracey KD, Shapiro ED, Vázquez M. Influenza vaccine given to pregnant women reduces hospitalization due to influenza in their infants. Clin Infect Dis 2010; 51(12):1355-1361. doi:10.1086/657309

14. Gray KJ, Bordt EA, Atyeo C, et al. Coronavirus disease 2019 vaccine response in pregnant and lactating women: a cohort study. Am J Obstet Gynecol 2021; 225(3): 303.e1-303.e17. doi:10.1016/j.ajog.2021.03.023

15. Shah ASV, Gribben C, Bishop J, et al. Effect of vaccination on transmission of SARS-CoV-2. N Engl J Med 2021 Sep 8; NEJMc2106757. doi:10.1056/NEJMc2106757

16. Eichner M, Schwehm M, Eichner L, Gerlier L. Direct and indirect effects of influenza vaccination. BMC Infect Dis 2017; 17(1):308. doi:10.1186/s12879-017-2399-4

17. Chua $H$, Feng $S$, Lewnard JA, et al. The use of test negative controls to monitor vaccine effectiveness: a systematic review of methodology. Epidemiology 2020; 31(1):43-64. doi:10.1097/EDE.0000000000001116

18. Teijaro JR, Farber DL. COVID-19 vaccines: modes of immune activation and future challenges. Nat Rev Immunol 2021; 21(4):195-197. doi:10.1038/s41577-021-00526-x

19. Zhang Y, Mao D, Roswit WT, et al. PARP9-DTX3L ubiquitin ligase targets host histone $\mathrm{H} 2 \mathrm{BJ}$ and viral $3 \mathrm{C}$ protease to enhance interferon signaling and control viral infection. Nat Immunol 2015; 16(12):1215-1227. doi:10.1038/ni.3279

20. Vivaldi Biosciences, Inc. Delta-19: Covid-19 + universal influenza combination vaccine. https://vivaldibiosciences. com/delta19. Accessed October 22, 2021.

21. Fierce Biotech. COVID-flu combo vaccine from Novavax sparks immune response to both viruses in animals. https://www.fiercebiotech.com/research/covid-flu-combovaccine-from-novavax-sparks-immune-response-to-bothviruses-animals. Accessed October 24, 2021.

Address: Sherif Beniameen Mossad, MD, FACP, FIDSA, FAST, Department of Infectious Diseases, G21, Cleveland Clinic, 9500 Euclid Avenue, Cleveland, OH 44195; mossads@ccf.org 